\title{
Appendix B for: Analytical methodology in the Applied Geochemistry Research Group (1950-1988) at the Imperial College of Science and Technology, London
}

\author{
Michael Thompson \\ School of Biological and Chemical Sciences, Birkbeck. University of London, Malet Street, London WC1E 7HX, UK \\ (e-mail:M.Thompson@bbk.ac.uk)
}

\section{APPENDIX B. CHEMICAL ANALYSIS ON GEOCHEMICAL FIELD COURSES}

An account of analysis in the AGRG could hardly be complete without reference to its field course in geochemical prospecting that was conducted every year in mid-winter in Cornwall (UK) (the course was run on at least one occasion in Ireland, with the laboratory set up in a local school), from the late 1950s to the mid 1990s. (It remained in existence until 2008 in a much attenuated form). The course was designed for students of the BSc in Mining Geology and the MSc in Mineral Exploration. In the early years of the course, many of the staff and the first-year research students of AGRG would participate as well. The weather was any combination of very cold, very wet and very windy. The course was memorable equally for the high degree of organization on the part of the staff, the good quality of the data that was achieved by students with just a few hours instruction in analysis, the difficult conditions under which the course was carried out, and the scarcely tolerable standard of the accommodation. The rigours of the course, in combination with a successful outcome in the form of real knowledge secured with considerable effort and discomfort, created an extraordinarily close working relationship between teachers and students that manifested itself as an enduring esprit de corps.

In the early years AGRG used the laboratory facilities of the Camborne School of Mines. From the mid 1960s, however, the course was based at Porthtowan, a small seaside village where Imperial College owned Tywarnhale Mine, a disused copper/tin mine used for teaching mining surveying. One cavernous building on the mine site could be temporarily converted into a makeshift laboratory. Until about 1985 the only service installed was electricity: the running water ran only in the adjacent stream, which included contributions from the acidic and cupriferous waters of several mine adits and the outfall from a sewage farm. Purified water for analytical purposes was made by deionizing this stream water. There was no heating and, on several occasions in the early days, the temperature was such

\begin{tabular}{lll}
\hline Day & \multicolumn{1}{c}{ Staff } & \multicolumn{1}{c}{ Students } \\
\hline 0 & Lab: drive laboratory equipment from London to Porthtowan. & Arrive late afternoon. \\
& Field: liaise with farmers about access to land. & Evening: choose exploration area on basis of known mine sites, \\
Evening: guide students in choice of exploration area. & geology etc. Plan sampling strategy. Assign sub-areas and sampling \\
& points to individual students.
\end{tabular}
and test laboratory facilities and equipment (first course only). Field: drop off students at starting points. Demonstrate sampling technique. Supervise in field. At dusk, pick up students at agreed rendezvous points and return to laboratory.

Late evening: check samples drying OK.

2 Lab: supervise students preparing and analyzing samples. Demonstration and practice of panning.

Evening: supervise students in assessing results and determining follow-up location and strategy.

Field: drop off students at follow-up site. Demonstrate sampling
technique. Supervise in field. At dusk, pick up students and return laboratory.

Late evening: check samples drying OK. Lab: supervise students preparing and analyzing samples. Return acetylene cylinder to depot. Supervise repacking of laboratory equipment (Second course only).

Evening: supervise students in assessing results.

\author{
Lab: Sieve samples and collect minus 80-mesh fraction. Weigh out \\ and decompose samples with nitric acid. Make to volume and analyse \\ by atomic absorption for 5-6 elements, usually $\mathrm{Cu}, \mathrm{Zn}, \mathrm{Pb}, \mathrm{Mn}, \mathrm{Fe}$, \\ Ag. Wash and dry all analytical glassware. \\ Evening: Map results and consider prospecting implications. Decide \\ on a follow-up area and define strategy, usually soil sampling on a \\ regular grid. \\ Field: Collect soil samples from predetermined points. \\ Lab: On return, stack samples in drying ovens. (About 100 samples.) \\ Lab: Sieve samples and collect minus 80 -mesh fraction. Weigh out \\ and decompose samples with nitric acid. Make to volume and analyse \\ by atomic absorption for 5-6 elements, usually $\mathrm{Cu}, \mathrm{Zn}, \mathrm{Pb}, \mathrm{Mn}, \mathrm{Fe}$, \\ Ag. Wash all analytical glassware. Help to repack laboratory \\ equipment and load into van (second course only). \\ Evening: Map results and consider final implications. \\ Repeat of days 1-4 for second course. \\ Return to London
}


that the benzene used in solvent extraction of metal complexes caused analytical problems by freezing. (Benzene is nowadays anathema, of course, because of its carcinogenic potential.) Any heating needed for analytical purposes was supplied by Primus stoves. After 1985, mains water was laid on and a welcome, but still wildly insufficient, degree of space-heating provided by butane-powered radiators.

The accommodation in Porthtowan, in two small local hotels, was equally challenging. Their heating and hot water systems were installed to a standard suitable for use only in high summer, with the consequence that bedrooms were cold and bedclothes damp and clammy. Old hands took electric blankets and surreptitiously left them switched on all day. Others not thus equipped slept in their clothes. Showering in a few litres of barely warm water was an ordeal often omitted.

The course was designed to demonstrate to students the scientific approach to prospecting by getting them to discover by geochemistry a mineral vein that had no visible surface expression. A number of suitable prospects in the area had been identified over the years. Until 1970, students would use colorimetric methods for determining specific elements, often $\mathrm{Cu}$ and $\mathrm{Sn}$, after decomposing the test portion by fusing it with potassium hydrogen sulphate. After 1971 AAS was used exclusively, and only the staff directly involved in the teaching went to Cornwall. It speaks volumes for the robustness of the Perkin-Elmer 403 instrument that it made the return journey at least 15 times without any incurred need for repair or even minor adjustment. (It also provided c. 2.5 million determinations during its lifetime in London.)

The inventory of tools, spares, chemicals and minor equipment needed, down to the last box of matches and Primus stove pricker, was drawn up and scrupulously overseen by Dick Campain. (After Dick left the AGRG, this task was managed equally well by Alban Doyle.) Although Dick never actually went to Cornwall, his was a very important function, because any oversight causing a downtime of more than an hour or two would have rendered impossible a successful completion of the course. To his credit (and Alban's), in the whole history of the course, such a misfortune never occurred. Personal computers were used in Cornwall at the earliest possible opportunity and thereafter every year, for the data storage and mapping, and for data manipulations (such as analysis of variance for the estimation of sampling and analytical precision, and principal components analysis) for identifying targets.

In its fully developed form, the course comprised a four-day cycle of activity for a group of 10-20 students, with two phases of activity, each comprising fieldwork followed by analysis of the samples generated. A broad-scale stream sediment survey covering c. $100 \mathrm{~km}^{2}$ was undertaken first, followed by a soil survey of a selected sub-area. Two such courses (BSc and MSc) were run in succession. (Field courses in geophysics were run concurrently.) Thus, the whole exercise took 10 days including travelling between London and Cornwall. A typical programme in the 1980s would be as outlined above.

Eventually (around 1990) proper laboratories with fume cupboards were installed at Tywarnhale but, unfortunately, shortly after that the College was obliged to close the mine and dispose of the site because frequent theft and vandalism was making it uninsurable and unsafe. The course continued in a modified form, however, with samples sent back to London for analysis, and was in existence until 2008, finally under the analytical supervision of Barry Coles. In the latter years the course incorporated field instruction in environmental assessment for MSc students in Environmental Science.

Analytical chemists attending the course in the AAS era (after 1970) include Answar Ahmed, Barry Coles, Alban Doyle, Mike Ramsey, Tony Thompson, Mike Thompson and Shirley Wood. Field supervisors in the same period were successively Tim Meyer, Dan Boyle, Martin Hale, Mike Ramsey and Peter Simpson. 